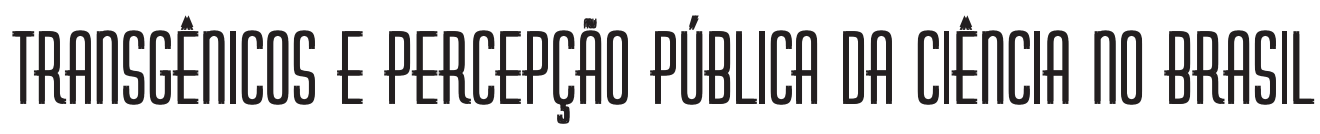

\author{
JULIA S. GUIVANT *
}

\section{INTRODUÇÃO}

Nos últimos anos, as biotecnologias agrícolas têm sido objeto de intensos debates no contexto internacional, com o papel da ciência no meio das controvérsias devido a incertezas científicas e sociais envolvidas ${ }^{1}$. Como parte do debate, levam-se em conta os resultados de inúmeras pesquisas de opinião pública que procuram captar a aceitação ou rejeição dos consumidores destas novas tecnologias quanto às implicações diretas que podem ter nas suas expectativas e crenças. Podem ser encontradas pesquisas encomendadas pelo setor industrial, assim como por órgãos governamentais e ONGs, juntamente com pesquisas independentes, de caráter mais acadêmico. Medir e avaliar as atitudes e percepções do público em relação aos transgênicos não é uma tarefa fácil. Os dados destas pesquisas, que deveriam se constituir em um input fundamental para processos de legislação e regulação das inovações científico-tecnológicas, têm passado a alimentar, com diferentes leituras de seus resultados, os diversos setores em confronto.

O debate não tem sido menos intenso no Brasil, particularmente a partir de 1998. Mas, o que sabemos sobre como se posicionam os consumidores, os produtores, os cidadãos no geral, a respeito deste tema? Quais são os tipos de informações com que nos dispomos para avaliar as tendências de aceitação dos organismos geneticamente modificados (OGMs) nos alimentos? Este artigo tem como objetivo principal a análise destas informações, comparando-as com as realizadas em outros paises, principalmente Estados Unidos e Europa. Um dos argumentos centrais deste trabalho é que, no Brasil, há uma significativa carência de dados sobre a opinião pública. Mas esta falta de pesquisas, ou seu número limitadíssimo, é aqui considerada uma evidência para caracterizar os termos do debate no Brasil, onde há uma desconsideração sobre a participação pública nos debates sobre transgênicos. Estes giram em torno de atores sociais organizados, que atuam sem representatividade ou sem procurar construí-la.

\footnotetext{
* Docente do Departamento de Sociologia e Ciência Política da Universidade Federal de Santa Catarina e coordenadora do Núcleo em Sustentabilidade e Redes Agroalimentares (NISRA).

Recebido em 09/2005 - Aceito em 02/2006.
} 
Também o número limitado de pesquisas expõe os limites da área de marketing, ainda assumindo uma perspectiva positivista sobre o consumidor. E, por último, podemos relacionar a falta de informação com a falta de problematização, no espaço acadêmico, sobre os conflitos ou consensos entre conhecimentos peritos e leigos, quando estão em questão inovações tecnológicas que envolvem riscos incertos. Não se procura entender as respostas dos consumidores-cidadãos nem as respostas dos formuladores de políticas públicas ou dos cientistas à opinião daqueles.

Na primeira parte, focalizamos as pesquisas realizadas no contexto brasileiro escolhendo as que foram destacadas como apoio a argumentos favoráveis ou contrários aos OGMs entre os principais atores sociais envolvidos no debate. Na segunda parte, consideramos as pesquisas realizadas em outros paises. Na terceira parte, analisamos os limites e vantagens das diferentes pesquisas aqui selecionadas como representativas, o que nos permite, nas conclusões, formular sugestões para pesquisas de opinião pública no Brasil.

\section{PESQUISAS NO BRASIL}

O tema da percepção pública da ciência no Brasil pode ser considerado como um não problema. O número de pesquisas é altamente limitado. Dividimos as pesquisas em três grupos: as que apresentam um caráter mais abrangente, no qual destaca-se somente uma; as que utilizam uma metodologia quantitativa para captar as posições do público sobre os transgênicos (e aqui incluímos as realizadas pelo Ibope, tanto para o Greenpeace quanto para a Monsanto); e as realizadas sem representatividade estatística, realizadas em eventos ou em homepages da Internet.

\section{A) Pesquisas de caráter abrangente e qualitativo}

Uma pesquisa inovadora sobre percepção pública da ciência, especialmente considerando sua metodologia, seu embasamento teórico e seus objetivos, foi realizada entre fins de 2002 e início de 2003 na Argentina, no Brasil, na Espanha e no Uruguai². Apesar das limitações para estabelecer generalizações sobre os resultados, dado que as amostras foram pouco representativas do universo, a pesquisa apresentou algumas importantes sugestões sobre relevantes tópicos do conhecimento científico e tecnológico, sobre o consumo de informação científica nessas sociedades e sobre a efetiva participação de seus cidadãos nos movimentos e debates em torno de temas controversos de ciência e tecnologia. Os transgênicos eram só um tópico entre vários outros envolvidos nas entrevistas.

Este projeto internacional tem como objetivo construir, futuramente, uma metodologia de pesquisa sobre a cultura científica adequada para entender as especificidades regionais ao mesmo tempo em que possam ser realizadas comparações internacionais mais amplas, uma das carências na área de percepção pública da ciência, como veremos no próximo item deste artigo. A metodologia que em geral se utiliza para pesquisas de cultura científica nos Estados Unidos, nos países da União Européia, 
no Canadá, na Austrália, na China e no Japão, entre outros, foi desenvolvida em 1972 pela National Science Foundation (NSF). Esses modelos de análise avaliam o nível de informação, atitudes e interesses dos indivíduos em relação à ciência, mas não revelam, por exemplo, seu grau de envolvimento com o avanço da pesquisa.

No Brasil, a pesquisa foi organizada pela equipe do Laboratório de Jornalismo da Unicamp (Labjor), coordenado por Carlos Vogt, que é também presidente da FAPESP3 ${ }^{3}$. As entrevistas envolviam um roteiro com 90 questões, eminentemente de caráter qualitativo. Dos quatro núcleos de questões - imaginário social, compreensão de conteúdos de conhecimento científico, processos de comunicação social da ciência e Participação Cidadã em questões de ciência e tecnologia -, o primeiro foi o mais extenso. E o conjunto de indicadores aí incluídos pretendia refletir, além das imagens que se têm da ciência, as idéias sobre sua utilidade, a valoração do conhecimento científico, a representação da ciência em sua relação com a sociedade e a vida cotidiana, os riscos que se associam à produção científica, a imagem dos próprios cientistas e a visão sobre o desenvolvimento da ciência local. Aqui radica a mais importante diferença com as pesquisas coordenadas pelo Ibope, abaixo descritas, que são quantitativas, oferecendo ao entrevistado opções fechadas de resposta. Na primeira amostra, foram consultadas 162 pessoas em Campinas, entre fevereiro e março de 2003. Posteriormente, a pesquisa foi estendida a São Paulo, onde foram aplicados 776 questionários, e a Ribeirão Preto, onde foram consultadas 125 pessoas.

Entre os resultados gerais, e sempre considerando o seu "caráter indicativo provisório", como é reconhecido pelos coordenadores internacionais da pesquisa, destacamos:

1) no imaginário social dos países estudados, prevalece uma imagem tríplice da ciência: como epopéia de "grandes descobertas", como condição de "avanço técnico" e como fonte de "melhoria da vida humana”.

2) no referente à informação sobre ciência e tecnologia: grande maioria das pessoas ouvidas considera-se "pouco informada" ou "nada informada".

3) confiança muito grande por parte do público nos cientistas como fonte de determinadas informações (sobre energia nuclear e biotecnologia), enquanto os jornalistas gozam nesse campo de credibilidade extremamente escassa.

Os resultados da pesquisa, explicitando a situação no Brasil, indicam que:

1) há uma visão da ciência como fonte de benefícios para a vida do ser humano, que conquista a maior adesão (46,9\% dos entrevistados). Um outro indicador da imagem positiva da ciência é a elevada concordância dos entrevistados nos quatro países (77\% na média e, no Brasil, 76,5\%) quanto à afirmação de que a principal causa da 
melhoria da qualidade de vida da humanidade é o avanço da ciência e da tecnologia;

2) a ciência não é considerada como uma espécie de panacéia universal. A maioria dos entrevistados discorda da afirmação de que a ciência e a tecnologia podem resolver todos os problemas $(82,7 \%$ no Brasil, $85,4 \%$ na Argentina, 82\% na Espanha e 93,3\% no Uruguai);

3) para se considerar o interesse da população no debate público sobre ciência e na necessidade de uma democratização do processo decisório sobre os rumos da pesquisa, um dado importante foram as respostas a questões que tentam captar a representação da ciência em relação à sociedade e à vida cotidiana. A ciência não é considerada um domínio exclusivo de mentes iluminadas. A maior parte dos brasileiros $(64,8 \%)$, uruguaios (56\%) e espanhóis (54\%) entrevistados discorda da afirmação de que "o mundo da ciência não pode ser compreendido pelas pessoas comuns". Também para uma fração importante dos entrevistados, a função política de decidir o que investigar ultrapassa a competência dos pesquisadores;

4) quando o assunto é biotecnologia, a confiança na fonte de informação se divide entre cientistas universitários e organizações nãogovernamentais (ONGs) de defesa do meio ambiente. Os brasileiros confiam mais nas ONGs ambientalistas, com uma baixa credibilidade nos jornalistas: $2 \%$ os consideram dignos de confiança.

O caráter inovador desta pesquisa fundamenta-se no seu caráter pioneiro no Brasil. Lamentavelmente, a amostra foi restrita e os transgênicos ocuparam um espaço limitado entre as diversas questões apresentadas aos entrevistados.

\section{B) Pesquisas quantitativas}

O IBOPE é responsável por pesquisas encomendadas pelo Greenpeace e que têm sido instrumento da ação dos grupos aglutinados na Campanha por um Brasil livre de Transgênicos, como também por uma pesquisa encomendada pela Monsanto. O Greenpeace, seguindo uma orientação internacional de contratar institutos de pesquisa de reconhecida competência e legitimidade, encomendou 3 pesquisas ao IBOPE, em 2001, 2002 e 2003.

O objetivo da última pesquisa foi o de levantar, junto à população no Brasil, opiniões sobre transgênicos, no período de 28 de novembro a 3 de dezembro de 2003. Foram utilizadas amostras representativas da população em estudo, estratificada com alocação proporcional à população de cada estrato (cada estado brasileiro). As regiões metropolitanas e as capitais de cada estado entraram na amostra. Dentro de cada estrato, nas regiões metropolitanas e nos demais municípios de cada estado, foram selecionadas amostras probabilísticas de conglomerados em 3 estágios. No primeiro estágio, foram selecionados probabilisticamente os municípios que formaram a amostra 
pelo método de Probabilidade Proporcional ao Tamanho (PPT), sendo a população de cada município tomada como base para tal seleção. No segundo estágio, agora dentro dos municípios selecionados no primeiro estágio, foram selecionados probabilisticamente os setores censitários onde as entrevistas foram realizadas também pelo método PPT. No terceiro estágio, as pessoas a serem entrevistadas foram selecionadas dentro dos setores censitários utilizando quotas proporcionais ${ }^{4}$.

As perguntas realizadas foram as seguintes:

1) $O$ (a) Sr.(a) já ouviu falar, ou nunca ouviu falar, em produtos transgênicos? (opções de resposta: já ouviu, nunca ouviu, não sabe);

2) Um organismo é chamado de transgênico, ou geneticamente modificado, quando é feita uma alteração no seu DNA, ou seja, no local onde estão as características de um ser vivo. Através da engenharia genética, genes são retirados de uma espécie vegetal ou animal e transferidos para outra. Esses novos genes sofrem uma espécie de reprogramação, podendo produzir um novo tipo de substância, diferente do organismo original. Caso você pudesse escolher entre um alimento transgênico e um alimento não transgênico, qual deles escolheria?

3) Na sua opinião, os alimentos com ingredientes transgênicos deveriam ou não deveriam trazer informação no seu rótulo?

4) Existem divergências entre os cientistas quanto aos riscos ao meio ambiente e à saúde com relação aos organismos transgênicos. O que o(a) sr.(a) acha que deveria ser feito enquanto as dúvidas não foram esclarecidas? Opções de resposta: deveriam ser proibidos, deveriam ser liberados, não sabe.

Entre os aspectos a destacar nesta pesquisa realizada em 2003, é a marcante evolução dos conhecimentos sobre transgênicos, alterando-se as relações entre 2002 e 2003 no que se refere à informação. Entretanto, o que se entende aqui por conhecimento é "ter ouvido falar", o que não necessariamente envolve um conhecimento mais preciso sobre o tema. No referente aos que preferem e os que não preferem alimentos transgênicos, podemos observar que as respostas contra o seu consumo não necessariamente envolvem conhecimento ou uma atitude que poderá se manifestar na prática de consumo, aspecto ao qual voltaremos no item final deste artigo.

$\mathrm{Na}$ pergunta 3, oferecem-se informações sobre o significado dos transgênicos. As dúvidas que surgem, e que serão discutidas em maior detalhe também no final deste artigo, referem-se a: 1) nível e compreensão que os entrevistados possam ter de um assunto altamente complexo a partir de uma breve e bastante técnica explicação e 2) pressuposto que permeia a pesquisa, e particularmente esta questão, de que uma maior informação é significativa para mudar a opinião dos entrevistados. Também a pergunta 4 pode deixar dúvidas sobre a influência da formulação das perguntas nas respostas dos entrevistados. 
Outra pesquisa realizada pelo Ibope foi encomendada pela Monsanto e também coloca ênfase central num conceito difuso e não definido sobre o conhecimento do público em relação aos transgênicos. O Ibope realizou 400 entrevistas telefônicas com pessoas de idade entre 16 e 64 anos, classes A e B, nas seguintes capitais: São Paulo (SP), Porto Alegre (RS), Brasília (DF), Rio de Janeiro (RJ), Belo Horizonte $(\mathrm{MG})$, Curitiba (PR), Fortaleza (CE), Recife (PE) e Salvador (BA). Os entrevistados deveriam ter assistido à "campanha de desmistificação" dos transgênicos veiculada nacionalmente entre 8 a 28 de dezembro de 2003, tendo como público-alvo donas-decasa, mães e estudantes. Entre as perguntas realizadas, contam-se:

1) Antes de assistir a esse comercial, qual era a opinião sobre os alimentos transgênicos? As respostas foram as seguintes: 1) Favorável 24\%; 2) Neutro 44\%; 3) Contra este tipo de alimento 27\%; 4) Não sabe responder $6 \%$.

2) Após assistir a este comercial, qual a sua opinião sobre os alimentos transgênicos? As respostas foram: 1) Favorável 45\%; 2) Neutro 32\%; 3) Contra este tipo de alimento $20 \%$; 4) Não sabe responder $4 \%$.

Também a pesquisa demonstrou que $70 \%$ dos entrevistados concordam com o fato que os transgênicos diminuem o uso de agrotóxicos e $60 \%$ acreditam que os alimentos transgênicos trazem benefícios para a população. E mais: $81 \%$ afirmam concordar com a afirmação de que a agricultura com biotecnologia pode melhorar nossa qualidade de vida. A principal conclusão da pesquisa foi a de que quanto mais informações, maior a aceitação, especialmente quando o assunto são transgênicos.

Comparando as pesquisas do Ibope para a Monsanto e para o Greenpeace, observam-se diferenças significativas nas respostas, fundamentalmente no que se refere à aceitabilidade dos transgênicos a partir da informação oferecida, seja no próprio questionário ou através do anúncio na televisão. Portanto, a informação, entendida da forma pouco precisa em que é utilizada nestas pesquisas, leva a posicionamentos e conclusões diferentes. Mas isto não tem sido visto como um problema nem pela Monsanto nem pelo Greenpeace, que passaram a utilizar os resultados das pesquisas para apoiar suas posições prévias.

Por exemplo, o diretor de comunicação da Monsanto, Lúcio Mocsányi, afirmou que "Os resultados comprovam que o problema não é a aceitação dos transgênicos, mas a falta de conhecimento sobre o tema. Quando a população tem acesso a informações corretas que sejam baseadas em informações científicas e sem desvios ideológicos, a aceitação aumenta"

Logo que os dados da pesquisa do Ibope para o Greenpeace foram publicados, a ONG organizou, em 26/1/2004, um ato de protesto na rampa do Palácio do Planalto, em Brasília (DF), para "alertar o governo federal que a ampla maioria da população brasileira é contra a liberação de organismos transgênicos no país". O protesto ocorreu no mesmo dia de uma reunião entre o Ministério do Meio Ambiente, a Casa Civil e o relator da Comissão Especial sobre Biossegurança para discutir o Projeto de 
Lei (PL) de Biossegurança. Também os dados apareceram no protesto organizado pelo Greenpeace em 25/8/2004 contra o regime de urgência de aprovação do Projeto de Lei de Biossegurança, com um ato em Brasília "para lembrar aos parlamentares que a ampla maioria da população (73\%) rejeita os transgênicos?

\section{C) Pesquisas não representativas}

Incluo aqui alguns exemplos de pesquisas que foram realizadas em eventos e em homepages, sem pretensão de representatividade, mas que também, como as pesquisas da Monsanto e do Greenpeace, passam a ser utilizadas de forma indiferenciada para apoiar argumentos a favor ou contra os transgênicos.

A Cooperativa Tritícola Mista Alto Jacuí (Cotrijal) promoveu uma enquete sobre transgênicos na entrada do parque da Expodireto em 2003, evento organizado com o apóio da Federação dos Trabalhadores na Agricultura do Rio Grande do Sul (Fetag). A consulta foi realizada entre as $8 \mathrm{~h}$ e as $12 \mathrm{~h}$, e os visitantes só votavam se quisessem. Um total de 3.406 pessoas aceitaram a proposta de responder sim ou não ao plantio de organismos geneticamente modificados (OGMs) no Brasil. Um percentual de $81,7 \%$ dos visitantes (produtores, expositores e representantes do meio urbano) se manifestaram favoráveis. $18,3 \%$ preferiram votar contra os transgênicos. O resultado foi interpretado pelo presidente da Cotrijal, Nei Mânica como um retrato do que ocorre no campo. $\mathrm{O}$ dirigente acredita que os produtores já conseguiram identificar os benefícios dos transgênicos (http://www.mnp.org.br/materias.php?mat_id=8977).

Uma enquete realizada em 2004 no site Ambiente Brasil averiguou o que o internauta pensa sobre os transgênicos. A enquete recebeu 1.140 respostas. Do total, 635 (56\%) afirmaram que não concordam com a liberação do cultivo e comercialização de OGMs porque "as informações disponíveis não são conclusivas sobre a questão". Entre os que concordam com o consumo de OGMs, estão os que acreditam que "transgênicos são uma boa alternativa para combater a escassez de alimentos" (92 votos, correspondentes a $8 \%$ ) e há também quem pense que "os estudos existentes comprovam as vantagens e benefícios dos transgênicos" (80 votos - 7\%). Para 24\% (268 votos) dos participantes da enquete, "transgênicos prejudicam o meio ambiente e a saúde humana". Os $6 \%$ restantes são de pessoas que não têm opinião formada sobre o assunto (Ambiente Brasil, 25 de agosto de 2003).

Outra pesquisa na Internet foi a realizada pelo Portal SRB (Sociedade Rural Brasileira), entre fevereiro e novembro de 2003. Mais de 5 mil visitantes únicos responderam à pergunta "Você é a favor ou contra a liberação do plantio de transgênicos no Brasil?". Do total exato de respondentes (5.455), a esmagadora maioria $(87,1 \%$ 4750 internautas) se disse favorável aos transgênicos. De acordo com a enquete, somente 705 visitantes $(12,9 \%)$ revelaram ser contra a autorização para cultivo de sementes geneticamente modificadas. (artigo de Ronaldo Luiz, Portal SRB, 28 de novembro de 2003)

Obviamente, os resultados das pesquisas na internet confirmam as posições dos sites, com as quais os visitantes tendem a identificar-se. 


\section{PESQUISAS INTERNACIONAIS}

No contexto dos Estados Unidos e da Europa, as pesquisas sobre percepção pública dos transgênicos têm se inscrito dentro de dois setores de pesquisa amplamente desenvolvidos: o dos estudos das representações sociais sobre ciência e as pesquisas sobre consumo.

Já desde o início dos anos 70, foi se consolidando a inquietude de conhecer com precisão como o público representava a atividade científica e técnica, frente à preocupação do que já se identificava como uma "crise científica" (CHEVEIGNÉ et al, 2002). No contexto europeu, a partir do início dos anos 70, as autoridades de Bruxelas começaram a encomendar os Eurobarómetros, surveys realizados no mesmo período, com o mesmo questionário, aplicados nos países da UE. Também diversas pesquisas têm sido realizadas na Europa, entre os anos 80 e 90, sobre o tema geral da ciência e da técnica. Desde 1991, começaram a se realizar surveys voltados especificamente para o tema das biotecnologias. Em 1995, um novo programa de pesquisa reúne 50 pesquisadores europeus para estudar a aceitabilidade pública das biotecnologias, incluindo estudos de políticas públicas e da mídia. Em 1996 e 2000, esta equipe foi ampliando-se para realizar pesquisas comparativas com outros paises europeus, com os Estados Unidos e Canadá (CHEVEIGNÉ et al, 2002: 118,119). Fundamentalmente, o enfoque destas pesquisas tem sido quantitativo, com a utilização de perguntas fechadas (dando ao entrevistado a possibilidade de escolher entre diferentes opções apresentadas).

Gradativamente, foi aumentando o número de pesquisas que visavam diversificar a metodologia, considerando-se insuficiente para captar as atitudes e percepções do público os dados obtidos em surveys quantitativos. Novas pesquisas passaram a incluir entrevistas semi-diretivas (o entrevistado responde livremente a partir de um número limitado de temas apresentados) e questionários com perguntas abertas (o entrevistado responde com seus próprios termos as questões apresentadas). Uma outra metodologia, cada vez mais difundida, é a de grupos focais.

No campo das pesquisas sobre opinião do consumidor, o modelo do consumidor racional foi assumido nos anos 50 nos programas dos departamentos de marketing, quando estes passaram a ser incorporados em algumas universidades americanas e européias. Até esse período, já tinham sido realizadas importantes pesquisas mercadológicas para procurar comercializar de forma bem sucedida novos produtos no mercado. Como Belk (1995) menciona, numa perspectiva histórica da área de marketing, nas pesquisas acadêmicas dos anos 50 e 60, as preferências dos consumidores eram consideradas como dadas e não como socialmente construídas ou influenciadas pelo mercado. As transformações nos enfoques nas pesquisas de marketing partiram de uma mudança no conceito do comportamento do consumidor. Primeiro, ainda nos anos 50, houve uma mudança parcial com a introdução de entrevistas em profundidade e métodos prospectivos com influências psicanalíticas, que configuraram o que passou a ser conhecido como pesquisas motivacionais. $\mathrm{O}$ seu foco era captar as emoções latentes dos consumidores em relação a determinados produtos. Mas as críticas, 
que enfatizaram que esta perspectiva poderia estar estimulando o potencial manipulador do marketing, apelando aos desejos subconscientes dos consumidores, levaram a que tal corrente motivacional perdesse espaço e legitimidade.

Nos anos 80, surgiu uma nova perspectiva sobre pesquisa de consumidores, dividindo o campo acadêmico do marketing, em duas correntes coexistentes: a perspectiva convencional e outra não convencional. A primeira corrente assume uma abordagem positivista, com pesquisas quantitativas, tendo como foco o processo de compra. A segunda coorrente parte de uma visão não positivista, com uso de métodos etnográficos, qualitativos, em diálogo com a sociologia e a antropologia, a partir de uma perspectiva multicultural, que não considera os consumidores como meros autômatos. Trata-se de uma abordagem que analisa os vários níveis de significações culturais imbricados nas práticas de consumo em determinados contextos sociais. A constelação de significados e práticas que caracterizam uma subcultura de consumo não se enquadraria exclusivamente em circunstâncias sócio-econômicas únicas. Pelo contrário, os membros de uma subcultura de consumo podem pertencer a diversas posições sociais (THOMPSON \& TROSTER, 2002).

Contam-se poucas pesquisas comparativas internacionais sobre percepção pública da ciência. A evidência sugere que as atitudes públicas diferem significativamente entre e dentro dos paises, e apresentam algumas transformações temporais. A pesquisa internacional mais abrangente sobre as atitudes dos consumidores foi a conduzida por Environics International em 2000 (ver HOBAN, 2004). Em 34 paises, foram realizadas 35 mil entrevistas perguntando se os benefícios das biotecnologias eram maiores que os riscos. O Brasil está incluído na pesquisa, assim como no mais recente Report de Environics International, mas lamentavelmente o acesso aos dados não é gratuito. Alguns padrões foram observados nas respostas: 1) Os Estados Unidos lideram o apoio às biotecnologias. como também nos paises menos industrializados, onde se observou um apoio bastante generalizado. 2) a maioria dos entrevistados (85\%) posicionou-se a favor do uso da biotecnologia para usos medicinais. Mas temas como biotecnologia animal ou rações animais transgênicas provocaram rejeições entre os entrevistados, o que pode ser interpretado como questões éticas e emocionais que permeiam as respostas. Outra pesquisa realizada em 2001 por Environics International (ver Hoban 2004), intitulada "Food Issues Monitor", em 10 paises, incluindo o Brasil, perguntou se os entrevistados estariam dispostos a consumir alimentos transgênicos se estes tivessem maior valor nutritivo. $O$ Brasil está entre os paises que apresentaram respostas favoráveis ao consumo, enquanto a maioria dos entrevistados, na Europa e na Austrália, afirmaram rejeitar os alimentos transgênicos ainda que tivessem maior valor nutricional.

Um aspecto bastante recorrente nas pesquisas de opinião que procuram estabelecer parâmetros comparativos é o confronto entre atitudes dos consumidores americanos e os europeus, tendendo-se a considerar, como vimos acima, os primeiros mais favoráveis aos transgênicos. A pesquisa acadêmica de Moon e Balasubramanian (2004) seria um exemplo de comparação da percepção pública sobre agrobiotecnologias nos Estados Unidos e no Reino Unido. Partindo do esquema conceitual de modelos de 
mediação, propõem que o impacto da confiança, senso de revelia contra a falta de respeito aos direitos dos consumidores, além de outras variáveis sócio-econômicas, influenciam significativamente as percepções de risco. Os consumidores britânicos são identificados com atitudes mais negativas em relação à biotecnologia que os americanos.

A seguir, apresentaremos pesquisas de consulta pública realizadas em vários países, dando destaque às que questionam estas afirmações generalizantes.

\section{A) Europa}

O Eurobarômetro, instrumento da União Européia para avaliar opinião pública, realizou surveys sobre percepção pública da biotecnologia em 1991, 1993, 1996, 1999 e 2002. Nesta última pesquisa, observa-se a tendência de 70,9\% de rejeição dos consumidores europeus com relação aos alimentos geneticamente modificados. $\mathrm{O}$ estudo demonstra que na Alemanha, França, Holanda e Itália a rejeição, inclusive, aumentou em comparação ao levantamento realizado em 1999, sendo que na União Européia como um todo houve uma leve diminuição da rejeição. Um aspecto importante em algumas pesquisas do Eurobarômetro tem sido incluir, entre 1996 e 1998 uma pergunta diferenciando 4 aplicações da biotecnologia: genética humana, novas medicinas, culturas protegidas de pragas, e melhoria nos alimentos. Á medida que o debate passou a estar mais difundido no contexto europeu, nota-se uma diminuição do apoio às duas aplicações médicas da biotecnologia. Estes dados apresentam um desafio difícil para a economia européia e perspectivas em risco para o desenvolvimento de avanços na área de saúde. Hoban (2003: 284) chama a atenção sobre a ausência desta questão nas pesquisas mais recentes do Eurobarômetro.

O foco nas biotecnologias agrícolas, e não nas implicações para a área de saúde, é observado, por exemplo, na pesquisa focalizando a opinião dos agricultores realizada na Alemanha pelo Instituto Wickert, especializado em pesquisas de opinião e de mercado e futurologia econômica (http://www.wickert-institute.com), e encomendada pelo Greenpeace. A amostra representativa incluiu 1.031 agricultores de todo o território alemão, procurando identificar sua opinião com relação ao uso da transgenia na agricultura. Trata-se do segundo levantamento com agricultores sobre o tema. Em 1997, o Greenpeace encomendou a mesma pesquisa ao Instituto Emnid, de Bielefeld. Na pesquisa de 2003 confirmara-se uma tendência que já se apresentava entre os consumidores alemães: $70 \%$ dos agricultores da Alemanha são contrários ao cultivo de transgênicos. Além da negativa com relação ao cultivo de transgênicos, a pesquisa também revela que a maioria dos agricultores alemães descarta o uso de ingredientes derivados de plantas transgênicas na ração animal (ANDRIOLI, 2003).

Na perspectiva comparativa dos resultados dos surveys, um dos resultados parece ir contra a interpretação bastante difundida de que, a um maior nível de educação, observar-se-ia um maior apoio às inovações técnico-científicas. Mas os paises do norte da Europa manifestam mais cautela e menos apoio incondicional à cultura científica, diferentemente dos países do sul da Europa. Isto pode dever-se ao 
fato de que, de acordo com Cheveigné et al (2000: 141), nos paises com maior nível de instrução, há uma certa saciedade e menos apetite para a cultura científica, especialmente por estarem sofrendo uma degradação ambiental causada pelo desenvolvimento industrial, enquanto nos paises do sul haveria maior expectativa para o desenvolvimento científico-tecnológico e menores preocupações ambientais. Este tipo de análise expõe a necessidade de se considerar aspectos culturais e valorativos na percepção pública das biotecnologias, e não exclusivamente procurar causas que focalizem na maior ou menor informação do público. Mas, também, poder-se-ia argumentar que nos países do sul da Europa, como Grécia e Espanha, o apoio às biotecnologias pode dever-se a uma menor informação e menos debates sobre suas consequências. Portanto, tampouco dispor de mais informação implicaria maior aceitação.

Estes aspectos culturais, sociais e éticos foram aprofundados no projeto The Public Perceptions of Agricultural Biotechnologies in Europe (PABE), encomendado pela União Européia e conduzido entre 1998-2000 por uma equipe interdisciplinar do Reino Unido, França, Alemanha, Itália e Espanha. Os objetivos eram o de apresentar elementos que permitissem compreender tais aspectos que influenciam as respostas públicas em relação aos transgênicos e identificar as implicações destes fatores para a formulação de políticas públicas.

Um exemplo da iniciativa das maiores empresas de biotecnologia na Europa foi a pesquisa realizada em 2002 no contexto da UE entrevistando 15.000 pessoas (ABE, 2002). Mas, seguindo a tendência de uma visão mais complexa da percepção pública da ciência e da tecnologia, em lugar de explicar atitudes negativas por falta de informação, a pesquisa enfatiza que, apesar de que as pessoas manifestem desejo de receber melhores informações, mais conhecimento não necessariamente significará maior aceitação. Isto se deveria fundamentalmente à falta de confiança da grande parte da população européia nas instituições da sociedade moderna. Entretanto, não foi identificada na pesquisa uma tendência anti-ciência entre os consumidores. A aceitação dos alimentos transgênicos dependeria de uma maior familiarização com suas aplicações e de uma confiança maior no papel das instituições governamentais na proteção dos consumidores.

Comparando-se os resultados de diversas pesquisas nacionais coordenadas por $\mathrm{ABE}$ com as realizadas pelo Eurobarômetro, foram encontradas respostas mais positivas. Isto é atribuído ao fato de que as questões foram geralmente mais detalhadas, testando as atitudes em relação a aplicações da biotecnologia, em lugar de isolar a tecnologia (seria mais fácil dar uma opinião sobre algo mais concreto).

A fim de se chegar a uma visão mais ampla da opinião pública sobre a pesquisa com biotecnologia na agricultura, a ABE contratou o KRC Research (2003) para compilar dados representativos de diversos estudos recentes. Esta revisão (European Views on Agricultural Biotechnology: An Overview of Public Opinion) $)^{8}$ procurou refletir a perspectiva pública sobre pontos vitais no debate referente à biotecnologia na agricultura. As pesquisas revisadas neste estudo são: The Grocer (2002), ABE (2001 e 2002), MORI (2002), The Consumer's Association (2002), Agricultural 
Biotechnology Council (2001), IfD Allensbach (2001), NOP (2001), Eurobarometer (2000), e do Departamento de Estado dos EUA (1999). Alguns dos pontos principais da revisão: 1) A mais grave preocupação dos consumidores europeus com a biotecnologia é a possibilidade de que os organismos geneticamente modificados (OGMs) afetem o equilíbrio da natureza e causem danos ao meio ambiente (49\%). Porém, dados mostram que as preocupações dos consumidores sobre o impacto ambiental podem cair ainda mais quando eles recebem informações sensatas sobre a biotecnologia. 2) Enquanto $66 \%$ dos consumidores europeus apóiam o uso da biotecnologia na criação de novos medicamentos, poucos dão seu apoio ao uso em alimentos GM. Líderes de opinião parecem simpatizar mais com a tecnologia. 3) Uma linguagem mais neutra leva a maiores níveis de apoio: 50\% dos entrevistados no Reino Unido dizem que apoiariam o uso da biotecnologia para a "produção de alimentos". Também, uma recente pesquisa MORI no Reino Unido mostra que as opiniões sobre o consumo de alimentos produzidos através da biotecnologia podem ser afetadas pela forma como uma questão é apresentada. 4) A maior parte da mudança de visão sobre o consumo de alimentos GM vem ocorrendo na Espanha (maior número de indecisos), Itália (idem), e Reino Unido (com menor probabilidade de consumo). As mudanças podem estar ocorrendo porque estes consumidores receberam informações com maior equilíbrio de adeptos e opositores da biotecnologia agrícola. 6) Entre os entrevistados, 58\% dizem que se percebessem a indicação de ingredientes geneticamente modificados no rótulo de um produto alimentício, não o comprariam. Dados da MORI (2002) mostram que $76 \%$ dos consumidores britânicos acreditam que a rotulagem deveria ser compulsória somente para produtos com ingredientes GM. 7) Entre os europeus, 64\% aprovariam a pesquisa científica com alimentos GM, enquanto a pesquisa MORI (2002) indica que 69\% dos consumidores no Reino Unido desejam que a pesquisa com produtos OGMs continue a ocorrer.

O RKC realizavem realizando pesquisas sobre opinião pública em relação aos transgênicos na Europa desde 2001, envolvendo 3.500 entrevistados no Reino Unido, França, Itália, Alemanha e Espanha9. Na pesquisa realizada em 2003, o Relatório procura mostrar as diversas nuances nas visões públicas sobre transgênicos. $\mathrm{O}$ debate é considerado como fluido, partindo-se da aceitação de que as percepções do público dependem de um amplo e complexo leque de fatores sociais. À medida que o debate sobre os transgênicos entra numa fase crítica na Europa, coincidentemente, os consumidores tendem a ser favoráveis à necessidade da escolha a partir da rotulagem $(82 \%)$.

\section{B) Estados Unidos}

Em diversas pesquisas (ver referências em HOBAN, 2004), têm sido observadas, entre os consumidores, várias oscilações sobre sua consciência em relação à presença de transgênicos nas prateleiras dos supermercados. No início dos anos 90 , esta consciência era muito baixa (só $1 / 3$ aproximadamente dos entrevistados em várias pesquisas tinham ouvido falar de transgênicos). Houve um pico em 1997 com o caso 
de Dolly, para cair novamente em 2000. Pesquisas realizadas em 2001 já apontavam um crescimento desta consciência, chegando a um pico de 53\%. Mas a partir desse momento, Hoban afirma que outros assuntos passaram a ganhar mais atenção da opinião dos consumidores. Mas a questão pertinente a ser colocada frente a estas oscilações é sobre até que ponto os americanos entendem os significados dos alimentos transgênicos.

Por exemplo, uma pesquisa realizada pelo grupo independente Pew Initiatiative on Food and Biotechnology, em 2001 poucos eram os consumidores que acreditavam existir um amplo uso das biotecnologias na cadeia alimentar. E ainda muito menor era o número dos que reconheciam que as estavam consumindo. Só 14\% dos entrevistados acreditavam, corretamente, que mais da metade dos alimentos continha OGMs. Estes dados não mudaram significativamente na pesquisa que Pew realizou em 2003, em parceria com The Mellman Group and Public Opinion Strategies. Em ambas pesquisas foram entrevistados, por telefone, 1000 consumidores $^{10}$. A pesquisa de 2003 incluiu um tema pouco trabalhado em outras pesquisas, qual seja, o da percepção pública dos riscos dos alimentos transgênicos: como os americanos sentemse em relação à forma em que os alimentos geneticamente modificados são regulados nos estados Unidos, e como vêem sua aplicação para os animais? Entre os importantes resultados, a análise da pesquisa destaca que os americanos tendem a se opor à proibição dos OGMs, mas são fortemente a favor de um processo regulador que envolva o FDA. Assim como foi também observado em pesquisas na Europa, os consumidores se manifestaram pouco confortáveis com as modificações genéticas em animais e apoiaram a pesquisa nas aplicações médicas dos OGMs.

Os dados das pesquisas de PEW não correspondem totalmente aos dados levantados pelo International Food Information Council (IFIC), com sede em Washington e vinculado às indústrias de bebidas, alimentos e agricultura. O IFIC passou a realizar freqüentes pesquisas sobre a consciência dos consumidores sobre os alimentos transgênicos a partir de 1997. Os resultados das pesquisas têm sido um ponto de referência importante nos debates científicos. A pesquisa mais recente do IFIC (Janeiro de 2004), a nona já realizada pelo Instituto, tomou uma amostra de 1.000 entrevistados, representando a população maior de 18 anos nos Estados Unidos, aos quais foi aplicado um questionário por telefone. Entre os resultados da pesquisa, observou-se um crescimento na aceitação da biotecnologia, a diferença do que foi observado pelas pesquisas de PEW. Entre 1997 e 2004, observou-se uma constante na possibilidade dos consumidores comprarem alimentos geneticamente modificados (em torno de 55\%). Um dado que diminuiu de forma significativa foi o número de pessoas que apóiam a política do FDA de rotulagem voluntária para OGMs, tendo passado de $78 \%$ a $53 \%$.

Os resultados das pesquisas realizadas pelo IFIC têm sido questionadas por Thomas Hoban (professor de Sociologia e Food Science da North Carolina State University), com 15 anos de estudos na área de percepções dos consumidores sobre os OGMs, como também por Carol Tucker Foreman, diretor do Food Policy Institute of the Consumer Federation of América (http://pewagbiotech.org 3/9/2004). Um dos principais questionamentos é que as pesquisas do IFIC incluem perguntas que tendem 
a influenciar respostas mais positivas. As questões enfatizam mais os benefícios do que as possíveis preocupações que podem estar envolvidas nas decisões, e isto pode explicar as diferenças significativas com as pesquisas realizadas por PEW ${ }^{11}$.

\section{C) Nova Zelândia}

Um exemplo que se destaca como modelo de pesquisa sobre percepção pública dos transgênicos foi a realizada na Nova Zelândia num programa pesquisa de 3 anos, financiado pela Foundation for Research, Science and Technology, e realizado pelas Universidades de Auckland e Massey (GAMBLE et al. 2000). A pesquisa partiu do reconhecimento da centralidade da participação pública no processo inerentemente sócio-político de avaliação dos riscos relacionados com tal inovação tecnológica. A metodologia envolveu 3 momentos. No primeiro, formaram-se 6 grupos focais para uma compreensão em profundidade das percepções de consumidores e agricultores. Os grupos focais são uma excelente técnica para explorar temas subjacentes em relação a conceitos compreendidos de uma forma restrita. Mas não são representativos. Por isto, o interessante desta proposta é a sua combinação com pesquisa quantitativa, como a realizada no segundo e terceiro momentos. No segundo, um estudo de manipulação dos atributos do produto foi realizado para avaliar a influencia dos transgênicos nas intenções de compra dos consumidores. Esta técnica permite identificar vários segmentos de consumidores trabalhando, neste caso, com 3 atributos (preço, benefícios e tecnologia), que eram avaliados em duas categorias de produtos (comida saudável, no caso de tomates, e snacks, no caso de bolachas de chocolate). A amostra foi de 115 entrevistados. E no terceiro momento, foi realizado um survey nacional com uma amostra representativa de 1.600 entrevistas por telefone para medir e explicar as atitudes dos consumidores.

Nas conclusões, os consumidores foram caracterizados como cautelosos na aceitação dos alimentos transgênicos. Na formação de atitudes em relação à ciência e à tecnologia, foram identificados dois processos. Um é o do risco-benefício trade-off, significando que os riscos são percebidos como mais fortes que os benefícios. Este balanço, entretanto, pode encaminhar-se para uma aceitação quando os benefícios relevantes são apresentados aos consumidores, como preço. A rotulagem foi considerada como decisiva para uma avaliação mais positiva.

Mais de 50\% dos consumidores entrevistados responderam corretamente mais de $75 \%$ das perguntas sobre questões básicas relacionadas com tecnologia e ciência dos alimentos, indicando que os consumidores têm condições de entender as informações factuais a eles apresentadas. Entretanto, houve uma baixa correlação entre a percepção que o consumidor pode ter de seu conhecimento e seu conhecimento efetivo. Se as pessoas pensam que estão bem informadas, ainda que não o estejam, podem prestar pouca atenção a campanhas de educação pública. Mas os autores do Relatório advertem de que é preciso tomar com cuidado esta observação, dado que uma significativa parte dos entrevistados considera que ninguém sabe com muita precisão sobre os transgênicos, e portanto não acreditam que as organizações que distribuem informação 
realmente estejam sabendo do que estão falando. Isto se relaciona com outro aspecto destacado na pesquisa: a confiança. As pessoas manifestaram querer informações de grupos independentes. O governo e a indústria foram considerados como não confiáveis, em contraposição às organizações de defesa dos direitos dos consumidores. As instituições científicas e de pesquisa apareceram como merecedoras de uma moderada confiança, devido ao fato de que receberiam mais fundos privados do que públicos para a pesquisa.

\section{D) Asia}

O Centro Asiático de Informações Alimentares (Asian Food Information Centre - AFIC) realizou, em 2002, um levantamento intitulado "O que os cidadãos da Ásia realmente pensam sobre alimentos geneticamente modificados", publicado em fevereiro de $2003^{12}$. Esta é a primeira pesquisa de opinião sobre o assunto realizada no continente e demonstra que a população local apóia o uso da biotecnologia na agricultura e na indústria alimentícia.

O AFIC entrevistou 600 consumidores da China, Tailândia e Filipinas. A maioria dos entrevistados (61\%) manifestou conhecer a presença de OGMs nos alimentos, até dando exemplos corretos, e sem mostrar significativas resistências (90\% manifestaram estar satisfeitos com o consumo de alimentos geneticamente modificados). Dos entrevistados, $66 \%$ disseram acreditar que serão beneficiados pela biotecnologia nos próximos cinco anos. A lista de vantagens apontadas espontaneamente pelos entrevistados foi quatro vezes maior que a de desvantagens. Os principais benefícios citados foram: qualidade dos alimentos, aumento de valores nutricionais e redução do uso de agroquímicos nas lavouras.

A pesquisa mostra que a população asiática acredita não saber muito sobre biotecnologia, o que corresponde com os dados das pesquisas realizadas em outros continentes, mas se interessa em ter acesso à informação, principalmente por meio da grande mídia (televisão, jornal e internet). Segundo o AFIC, esta pesquisa tem grande utilidade, uma vez que sempre foram usados levantamentos feitos na Europa como medida da opinião pública asiática.

Em 2003, o AFIC realizou uma pesquisa qualitativa, publicada em 2004, "Communicating with Consumers on Food Biotechnology". A metodologia utilizada foi a de grupos focais formados nas Filipinas, China e India. Os resultados da pesquisa quantitativa anterior foram confirmados: apesar da pouca informação precisa sobre os OGMs, os consumidores se manifestaram favoráveis e abertos à sua introdução na cadeia alimentar. Os consumidores, entretanto, manifestaram-se desconhecedores dos temas que envolvem os debates mais intensos entre stakeholders, como a transferência horizontal de genes. Os cientistas, assim como organizações do tipo FAO, foram percebidos como confiáveis por passarem informações neutras. Neste ponto, podemos ver como apesar dos conflitos e debates sobre as biotecnologias, ainda a imagem da ciência, assim como foi visto na pesquisa coordenada por Vogt no Brasil, mantém-se significativamente intocada. 
A opinião dos asiáticos a respeito da biotecnologia é importante, não só por representarem cerca de $60 \%$ da população mundial, mas também pelo fato de serem grandes importadores e produtores de transgênicos. Segundo o ISAAA (Serviço Internacional para a Aquisição de Aplicações de Agrobiotecnologia), a China é o quarto maior produtor de organismos geneticamente melhorados, com 2,1 milhões de hectares ( $4 \%$ da área mundial plantada com OGMs). Além disso, o país investe pesadamente em biotecnologia. Até 2005, calcula-se que chegue a investir US\$500 milhões por ano no setor.

\section{AVALIAÇÃO DAS PESQUISAS}

\section{A) Cuidados metodológicos}

Algumas das pesquisas sobre percepção pública da ciência e/ou inovações tecnológicas apresentam sérios limites. Devem ser consideradas como ferramentas que permitem formar visões das inclinações públicas, mas revelando muito pouco sobre os complexos mecanismos envolvidos na formação de opinião. Entre os problemas que podem ser encontrados em várias das pesquisas comentadas neste artigo, mencionamos alguns a seguir:

1) Há limites nas comparações de resultados de pesquisas realizadas em tempos e lugares diferentes. As respostas dependem significativamente do contexto de aplicação da pesquisa. Ao comparar dados de países, regiões ou categorias de consumidores por nível de renda, educação, idade, sexo, estado civil, dentre outros, corre-se o risco de extrair conclusões pouco plausíveis. Desta maneira, os dados estatísticos projetados destas pesquisas podem indicar índices de aceitabilidade ou rejeição de transgênicos maiores dos que seriam obtidos em relação às efetivas práticas de consumo dos entrevistados. Além disto, surge a dúvida se um país pode ser tomado como unidade de análise. Isto é, até que ponto as atitudes diferentes se devem à nacionalidade? Será que as diferenças entre os países são superiores àquelas que podem decorrer de outros fatores, como nível cultural, sexo ou orientações políticas? As respostas a estas questões, como mostram Cheveigné et al (2002: 154), são complexas e demandam muito cuidado da parte dos pesquisadores.

2) limites em comparar pesquisas realizadas por instituições diferentes (ver por exemplo, KELLY, 2002; KRC, 2003).

3) O tamanho da amostra e os métodos utilizados para a escolha dos entrevistados podem interferir nos resultados. Por exemplo, a forma em que é realizada a pesquisa varia entre entrevistas realizadas por telefone (mais comum nos Estados Unidos) ou face a face (mais comum em países em desenvolvimento e Europa). Também podem emergir diferenças significativas entre pesquisas qualitativas e quantitativas, 
que captam diferentes tipos de respostas. Por isto, seria recomendável a complementação de ambas.

4) $O$ tipo de informação básica oferecida aos entrevistados pode influenciar de forma decisiva os resultados. Hoban (2004) aponta que o termo "biotecnologia" tem sido mais bem aceito em alguns países que o de "organismos geneticamente modificados". Apesar de que a diferença da terminologia pode ocasionar oscilações do nível de aceitabilidade entre $10-20 \%$, as pesquisas tendem a utilizar os conceitos de forma indiferenciada.

5) Uma das questões mais comuns para explicar as atitudes favoráveis ou desfavoráveis do público em relação aos transgênicos, seja em pesquisas qualitativas ou quantitativas, ou em meras referências gerais sobre a questão, é a do nível de informação dos entrevistados. Sem negar o papel que esta possa efetivamente ter na influência das respostas, há um aspecto que deve ser diretamente desmistificado: mais informação não leva, necessariamente, nem à aceitação de uma inovação tecnológica controversa, nem à aceitação de definições de riscos apresentadas pelo discurso científico. Mais informação, sem dúvida, é um requisito imprescindível para aumentar o poder decisório dos cidadãos, mas não para diminuir o fosso que possa existir entre leigos e peritos, nem o fosso que possa existir entre o público e os setores tanto favoráveis quanto contrários aos transgênicos.

\section{B) Limitações do modelo do déficit de informação}

1) $O$ modelo de comunicação da ciência que enfatiza o papel da informação para a superação de tal fosso tem sido identificado como modelo do déficit (IRWIN \& WYNNE, 1996; GUIVANT, 1998). Os leigos tendem a ser identificados como receptores passivos de estímulos independentes, percebendo os riscos de forma não científica, pobremente informada e irracional. Com a informação supostamente comunicada de forma neutra e objetiva, os leigos superariam resistências ou posições obscurantistas. $\mathrm{O}$ pressuposto é de que as pessoas melhor educadas e melhor informadas são as mais favoráveis às inovações científicas e tecnológicas. Mas o que diversos estudos na área de percepção pública da ciência têm demonstrado (por exemplo, ver PETERS, 2003), é que não há um vínculo direto entre conhecimento e atitudes. As correlações podem se dar nas duas direções. Pessoas com profundo conhecimento sobre o tema podem ser fortemente a favor ou contra uma particular inovação, assim como as pessoas pobremente informadas. E é até mais comum que as pessoas melhor informadas tendam a ser mais reticentes em assumir posições claramente a favor ou contra. Peters (2003) explica que isto acontece 
porque as pessoas melhor educadas e com maior informação tendem a considerar diversos pontos de vista, o que torna mais difícil tomar uma decisão final.

Portanto, também não necessariamente é válido afirmar que, se as respostas são de aceitação, é porque existe informação. As opiniões são produto de complexos processos que dependem de modelos cognitivos, incluindo elementos factuais mas também considerações éticas e culturais, que não podem ser modificadas simplesmente com mais informação. Claro que é melhor uma opinião que se apóia em mais informação do que uma que não se apóia em informação alguma.

Para ilustrar as complexas relações entre informação e aceitação dos transgênicos, podemos considerar uma das pesquisas do International Food Information Council (IFIC) sobre as opiniões dos americanos sobre o uso de biotecnologias nos alimentos, realizada em setembro de 2001 . Só 33\% da população tinham conhecimento de que alimentos transgênicos estavam à venda nos supermercados. Entre aqueles que pareciam mais bem informados, foram poucos os que conseguiram dar exemplos de produtos que tinham sido geneticamente modificados. Joly (2004) pergunta-se se esta desinformação poderia ser entendida como indiferença frente aos riscos. Ele argumenta que esta não seria a resposta, aproveitando uma comparação com uma pesquisa sobre percepção de riscos de alimentos transgênicos coordenada por SOFRES, também em 2001, entrevistando consumidores na França, Alemanha, Inglaterra e Estados Unidos. Um dos resultados identificou atitudes mais positivas nos Estados Unidos, mas numa percentagem que não era significativa para explicar a aceitação de uns e a rejeição dos europeus. A maior percentagem de oposição aos transgênicos (afirmando a precaução como orientação para evitar alimentos transgênicos) foi a mesma nos Estados Unidos e na Inglaterra $-1 / 4$ dos entrevistados. Também o FDA, realizando pesquisa com grupos focais, mostrou indignação dos participantes, não por uma preocupação com a saúde, mas porque se sentiam violentados, com as transformações que estão acontecendo nos alimentos sem serem informados (JOLY, 2004).

Utilizando-se grupos focais como metodologia, os resultados não mostram significativas diferenças entre consumidores dos Estados Unidos, da França, Reino Unido, Espanha, Itália e Alemanha. As pesquisas que procuram captar atitudes individuais isoladas apresentam limitações para explicar diferentes tendências sobre os OGMs.

Portanto, este tipo de metodologia permite aprofundar nos fatores culturais que afetam a forma com que as pessoas estimam os riscos, tal como tem sido já extensamente estudado pelas teorias sociais da ciência (JASSANOFF et al, 1996). De acordo com Wynne (2002), tal percepção pode ser significativamente afetada pela confiança nas instituições que controlam os riscos tecnológicos e ambientais entre os leigos. Isto é, as respostas leigas aos riscos e as informações sobre os riscos se apóiam numa racionalidade que emerge de suas experiências e julgamentos de credibilidade e confiança em relação às instituições que assumem o seu controle, envolvendo 
questões como o desempenho, as atitudes, a abertura ou transparência das indústrias e das agências reguladoras dos riscos. Entretanto, é bastante comum observar que, caso se detecte numa pesquisa de opinião uma atitude de desconfiança, isto passa a ser interpretado como ignorância, irracionalidade, ou expectativas ingênuas de margem zero de riscos, sem se ver que estão em jogo diferentes racionalidades, julgamentos que não são, meramente, um contexto subjetivo dos conflitos sobre riscos.

2) Dificuldade de entender como podem emergir opiniões que parecem ser consistentes, mas que podem ocultar ambigüidades e uma pluralidade de sentidos. A pluralidade não corresponderia só a posições diferentes, mas também seria um atributo dentro de cada posição. Esta complexidade não é fácil de ser captada por discursos científicos que pressupõem uma visão unidimensional do que pode estar certo ou errado, deixando a ambigüidade no campo da ignorância ou da falta de informação (WYNNE, 2002: 461), nem por pesquisas quantitativas de percepção dos consumidores. A ambigüidade pode estar permeando os valores de um entrevistado, e também pode estar presente na inconsistência entre as atitudes ou preocupações manifestadas numa entrevista e as práticas efetivas da pessoa. Isto é particularmente frequente em relação aos riscos à saúde e consumo de alimentos (RIMAL et al, 2001).

3) Nas pesquisas quantitativas de opinião, é a limitada valorização da influência do ambiente/entorno sobre as decisões de consumo ou percepções de risco que pode ter um papel central. Por isto coloca-se como necessária a superação do modelo psico-social do comportamento humano. Este modelo parte de atitudes individuais para predizer comportamentos concretos e futuros, tomando, por exemplo, diversos indicadores fixos para identificar uma consciência ambiental. Mas, também as pesquisas qualitativas, que partem de painéis domiciliares nos quais as amostras são pouco representativas e/ou os participantes têm pouco conhecimento ou orientação sobre o que significam os transgênicos, pressupõem tal modelo psico-social de comportamento humano.

Em lugar de tomar como central o individuo e suas atitudes em relação a um aspecto de suas práticas de consumo, no modelo das práticas sociais são destacadas as práticas de consumo efetivas, situadas no tempo e no espaço, que um indivíduo compartilha com outros atores sociais (SPAARGAREN, 2003). E, em lugar de focalizar os aspectos isolados do comportamento, procura-se estabelecer o modo como um grupo de atores sociais vincula diversas práticas cotidianas para reduzir impactos ambientais nas suas rotinas diárias. A metodologia dos grupos focais permite captar esta complexidade de valores e a inserção dos mesmos numa rede de práticas sociais. Algumas das pesquisas realizadas na Europa, nos Estados Unidos e na Ásia, seguem 
esta metodologia. Mas também a metodologia dos grupos focais apresenta limitações e, por isto, sua complementação com outras estratégias é fundamental.

4) Até aqui, apresentamos observações sobre como interpretar as posições dos entrevistados. Um outro questionamento, conectado com este, mais difundido especialmente no contexto das teorias sociais da ciência, refere-se à necessidade de se focalizar nos valores e visões de mundo que assumem os cientistas e pesquisadores, assim como formuladores de políticas públicas. No próprio desenho da tecnologia estão imbutidos tais valores, e não exclusivamente nos seus impactos. Considerandose esta perspectiva, o levantamento de opiniões deveria envolver a própria pesquisa, abrindo uma nova agenda de consulta pública, procurando evitar uma visão da ciência sem conflitos e sem ambigüidades.

Jasanoff et al (1995), especialmente apontando os limites da "ciência reguladora," consideram que os peritos, ao lidar com fatos incertos, utilizando, às vezes, paradigmas teóricos inconsistentes e com métodos de estudo questionáveis, assumem decisões carregadas de valores, como graus de aversão aos riscos ou de tolerância.

\section{CONCLUSÕES}

No Brasil, o limitado número de pesquisas sobre percepção pública da ciência pode relacionar-se com a falta de problematização sobre o papel dos cidadãos no processo de dar forma às inovações científicas e tecnológicas (GUIVANT, 2002). Este quadro contrasta significativamente com a relevância que as pesquisas sobre avaliação de tecnologias, sobre as políticas científicas, sobre a economia da transformação tecnológica, etc, têm assumido nas últimas décadas na Europa e nos Estados Unidos.

As inúmeras pesquisas de percepção da ciência e das biotecnologias oscilam entre enfoques quantitativos convencionais e uma crescente complexificação da metodologia, combinando-se estudos qualitativos e quantitativos de diversos tipos. Neste artigo, analisamos a contribuição significativa da perspectiva social-construtivista dos estudos sociais sobre a ciência, especialmente a partir da intensificação das resistências públicas às inovações biotecnológicas, em meados da década de 90, em vários paises europeus. A partir desta perspectiva, podem ser analisadas as diversas opiniões do público e sua compreensão sobre o desenvolvimento científico-tecnológico, de uma maneira que evite interpretações tendenciosas que exclusivamente confirmem argumentos que determinados grupos sociais, políticos ou econômicos, que encomendam as pesquisas, querem legitimar. 


\section{BIBLIOGRAFIA}

ABE (Agricultural Biotechnology in Europe) Public attitudes to Agricultural Biotechnology. Issue paper N.2. 2002, 12ps.

ANDRIOLI, A.I. Agricultores alemães são contra transgênicos. 2003, http:// www.idec.org.br/noticia.asp?id=1758, 1/10/2003.

BELK, R. Studies in the new consumer behaviour. In: MILLER, D. (ed.), Acknowledging consumption. A review of new studies. New York: Roultedge, 1995.

CEVEIGNÉ, S.de; BOY, D. \& GALLOUX, J-C. Les biotechnologies en débat. Pour une démocratie scientifique. Paris: Voix et Regards. 2002, 254ps.

GAMble, J. ; MUGGLESTON, S.; HedDERley, D.; PARMINTER, T. \& RICHARDSON-HARMAN, N. Genetic Engineering: the public's point of view. Report of the Horticulture \& Food Research Institute of New Zeland. 2000, 78ps

GUIVANT, J. "Trajetórias Das Análises De Risco: Da Periferia Ao Centro Da Teoria Social." Revista De Informações Bibliográficas -Associação Nacional De PósGraduação em Ciências Sociais N.46: 1998, p. 3-38.

GUIVANT, J. Heterogeneous and unconventional coalitions around global food risks: integrating Brazil into the debates. Journal of Environmental Policy and Planning. V.3, n.2: 2002, p. 231-245

HOBAN, T. Public Concerns about Biotechnology. In: SERAGELDIN, I. \& PERSLEY, G.J. (eds), Biotechnology and Sustainable Development. Voices of the South and North. CAB International, 2003.

HOBAN, T. Public attitudes towards agricultural biotechnology. ESA Working Paper N. 04-09. FAO, 2004.

HOUSE OF COMMONS, ENVIRONMENT, FOOD AND RURAL AFFAIRS COMMITTEE. Conduct of the GM public debate. Londres: The Stationery Office. 2003, 78ps.

IRWIN, A. \& WYNNE, B. Misunderstanding science? The public reconstruction of science and technology. Cambridge: Cambridge University Press, 1996.

JASANOFF, S.; MARKLE, G.; PETERSEN, J. \& PINCH, T. (eds.) Handbook of science and technology studies. Londres: Sage Publications, 1995.

JOLY, P-B. Science, Market and Democracy in a Global Uncertain World. A comparative analysis of the construction of GMos as a public problem in France and the USA. Paper apresentado no Seminário Internacional Tecnologias, riscos e incertezas: Desafios para a democratização da ciência. UFSC, Florianópolis, abril 2004.

KELLY, J. Public attitudes to the commercialization of GM crops. London: COI Communications. 2002 www.gmnation.org.uk/docs/desk_research01.doc

KRIEGER RESEARCH CENTER KRC European Views on Agricultural Biotechnology: an overview of public opinion. London. 2003, 16ps.

MOON,W. \& BALASUBRAMANIAN, S. Public Attitudes toward Agrobiotechnology: The Mediating Role of Risk Perceptions on the Impact of Trust, Awareness, and Outrage. Review of Agricultural Economics 26 (2): 2004, p.186-208 
PETERS, H.P. Moulding public opinion - truth and myth. Magazine of European Research. N.39, Novembro 2003.

RICHTER, T. Conceptual basics for national standardized data gathering concerning organic consumption and influencing factors. In Proceedings of the $14^{\text {th }}$ IFOAM Organic World Congress. Victoria, Canada, 2002: 186-187.

RIMAL, A.; FLETCHER, S.; MCWATTERS, K.; MISRA, S. \& DEODHAR, S. Perception of food safety and changes in food consumption habits: a consumer analysis. International Journal of Consumer Studies, 25, 1: 2001, p. 43-2.

SPAARGAREN, G. Sustainable consumption: a theoretical and environmental policy perspective, Society and Natural Resources, 16: 2003, p. 687-701

THOMPSON, C. \& TROESTER, M. "Consumer Value Systems in the Age of Postmodern Fragmentation: The Case of the Natural Health Microculture.", Journal of Consumer Research, Vol. 28, Março 2002.

WYNNE, B. Risk and environment as legitimatory discourses of technology: reflexivity inside out? Current sociology, May, Vol. 50 (3): 2002, p. 459-477.

\section{NOTAS}

1. A terminologia tende a ser bastante confusa no tema das biotecnologias. Utilizo aqui indistintamente alimentos OGMs, biotecnologias agrícolas e transgênicos (uso mais comum no Brasil) para me referir aos alimentos que contem organismos geneticamente modificados (técnicas que permitem a transferência de genes funcionais de um organismo para outro, incluindo aqueles de uma espécie para outra)

2. Ver Revista Pesquisa, Fapesp, No. 95, 2004.

3. Um antecedente a este tipo de pesquisa foi a realizada em 1987, "O que o brasileiro pensa da ciência", sobre a imagem que a população urbana do país tinha da ciência, concebida pelo CNPq junto com o Museu de Astronomia e Ciências Afins (Mast) e realizada pelo Instituto Gallup. A partir das respostas de 2.892 pessoas (1.409 homens e 1.483 mulheres), com mais de 18 anos e de todas as classes sociais, a 27 questões, a sondagem mostrou, entre outros dados, que $52 \%$ das pessoas ouvidas achavam o país atrasado em pesquisa e que $71 \%$ delas manifestavam algum ou muito interesse por descobertas científicas. Revelou também que os cientistas ocupavam, em sua visão, o quinto lugar entre os profissionais que mais contribuíam para o desenvolvimento do país, atrás de agricultores, industriais, professores e médicos (ver Revista Pesquisa, Fapesp, N.95).

4. As variáveis consideradas foram:

Sexo: masculino/feminino de acordo aos dados do censo de 2000

Grupo de idade: $16-17,18-24,25-2930-39,40-49,50$ anos e mais.

Atividade: setor de dependência, agricultura, indústria de transformação, indústria de construção, outras indústrias, comércio, prestação de serviços, transporte e comunicação, atividade social,administração pública, outras atividades, estudantes e inativos (com dados ajustados pela PNAD 2001)

Posição na ocupação: economicamente ativo, não economicamente ativo.

Localização geográfica: setores censitários do Censo demográfico de 2000.

5. www.srb.org.br/index.php3? news $=2517$

6. www.greenpeace.org.br/consumidores/?conteudo_id $=993 \&$ content $=1$

7. www.greenpeace.org.br/transgenicos/?conteudo_id $=1648 \&$ sub_campanha $=0$

8. abeurope.dynamicweb.dk/images/files/Public_opinion_overview_on_biotechnology.pdf

9. http://www.europabio.org/documents/140404/ne_140404_t_1.htm

10. http://pewagbiotech.org/research/2003update/

11. Alguns exemplos das perguntas: a)"How likely would you be to buy a variety of produce, like tomatoes or potatoes, if it0 had been modified by biotechnology to taste better or "fresher?"; b)"How likely would you be to 
buy a variety of produce . if it had been modified by biotechnology to be protected from insect damage and required fewer pesticide applications?"; c) "Biotechnology has also been used to enhance plants that yield foods like cooking oils. . Would this have a positive effect, a negative effect, or no effect on your purchase decision?"; e d) "Some critics ... say that any food produced through biotechnology should be labeled even if the food has the same safety and nutritional content as other foods. However, others, including the FDA, believe such a labeling requirement has no scientific basis, and would be costly and confusing to consumers. Are you more likely to agree with the labeling position of the FDA or with its critics?" (http://www.ific.org/research/upload/ 2004-Biotech-Consumer-Research.pdf, 7/9/2004)

12. http://www.afic.org/ 


\title{
JULIA GUIVANT \\ TRANSGÊNICOS E PERCEPÇÃO PÚBLICA DA CIÊNCIA NO BRASIL
}

\section{Resumo}

Este artigo tem como objetivo a análise de pesquisas sobre percepções de consumidores, produtores, cidadãos em relação ao uso de alimentos transgênicos, estabelecendo comparações entre as desenvolvidas no Brasil, na Europa, na Ásia e nos Estados Unidos. Tais pesquisas têm passado a desempenhar um papel central nos debates sobre seus riscos tanto entre os setores a seu favor quanto aos que se manifestam contrários a tal uso. Um dos argumentos centrais deste trabalho é que no Brasil há uma significante carência de dados sobre tal percepção pública. A falta de pesquisas, ou seu número limitadíssimo é aqui considerado uma evidência para caracterizar a trajetória da polêmica no Brasil, com uma significativa ausência de participação pública nos debates sobre transgênicos. Estes giram em torno de atores sociais organizados, que atuam sem ou com parcial representatividade. Também o número limitado de pesquisas expõe os limites da área de marketing, ainda assumindo no Brasil uma perspectiva positivista sobre o consumidor. E, por último, consideramos que podemos relacionar a falta de informação com a falta de problematização no espaço acadêmico sobre os conflitos ou consensos entre conhecimentos peritos e leigos quando estão em questão inovações tecnológicas que envolvem riscos incertos. Na primeira parte focalizamos nas pesquisas realizadas no contexto brasileiro, escolhendo as que passaram a ser destacadas como apóio a argumentos a favor ou contra os transgênicos entre os principais atores sociais envolvidos no debate. Na segunda parte consideramos as pesquisas realizadas em outros paises. Na terceira parte analisamos os limites e vantagens das diferentes pesquisas aqui selecionadas como representativas, o que nos permite nas conclusões formular sugestões para pesquisas de opinião pública no Brasil não só sobre transgenicos, mas também sobre percepção publica da ciência.

Palavras-chave: percepção de riscos, percepção pública da ciência, transgênicos

\section{GMOS AND THE PUBLIC PERCEPTION OF SCIENCE IN BRAZIL}

\begin{abstract}
This article has as its main objective the analyses of different researches on the perception of consumers, farmers and citizens in general in relation to the use of Genetically Modified Organisms (GMOs) in food production and consumption. We established a comparative perspective between the researches developed in Brazil,
\end{abstract}


in Europe, in Asia and in the United States. The researches themselves, with their results, had become a central part on the debates about GMOs risks, both among the sectors that emphasized them as well as in the sectors that denied them. One of our key arguments is that in Brazil there is a lack of researches in the subject on public perception of risk. This situation can be considered as an evidence of the lack of interest in the public participation in the debates about GMOs. These had been mainly controlled by organized social actors, without any or with only partial representation. Also the limited number of researches in Brazil showed the limits of the marketing area (that had assumed these work in other countries), still assuming a positivistic perspective on the consumers. And finally, we argue that the in the Brazilian academic field there is a no problematization of conflicts or consensus between lay and expert people in the debate about GMOs risks. In the first part of the article we focused in the analysis of the types of researches that had taken place in Brazil, choosing the ones that had been used as supporting different arguments in relation to GMOs by the social actors involved in the debate. In the second part we considered the researches developed in other parts of the world. And in the third part, we analyse the constrains and opportunities that different researches here selected as the most interesting can present for the understanding of the global debate on GMOs and also showing one interesting road for future researches in Brazil on public perception, not only of GMOs, but also of science.

Keywords: risk perception, public perception of science, genetically modified organisms.

\section{CRISTIANO LENZI}

\section{PARA UMA IMAGINAÇÃO SOCIOLÓGICA DA ECOLOGIA: UMA ANÁLISE DO PENSAMENTO DE ANTHONY GIDDENS}

No presente texto tomamos a obra de Anthony Giddens para avaliar a forma pela qual a questão ecológica veio a ser incorporada pela teoria social. Giddens se tornou nas últimas décadas num dos grandes nomes das ciências sociais contemporâneas e, no decorrer dos últimos anos, passou a ter uma intervenção importante no cenário político com sua proposta de construção de uma Terceira Via. Ao mesmo tempo, ao longo desse período, muitos trabalhos das ciências sociais passaram a expressar também um interesse cada vez maior pelo tema ambiental. Um fenômeno que pode ser visto até mesmo nos próprios trabalhos de Giddens onde iremos encontrar uma referência permanente aos temas do risco, perigo, segurança e de conceitos como desenvolvimento sustentável, modernização ecológica e sociedade de risco. Em razão desse quadro geral, parece pertinente avaliarmos o que um teórico social como Giddens tem a nos dizer sobre a crise ecológica contemporânea. No texto procuramos mostrar 